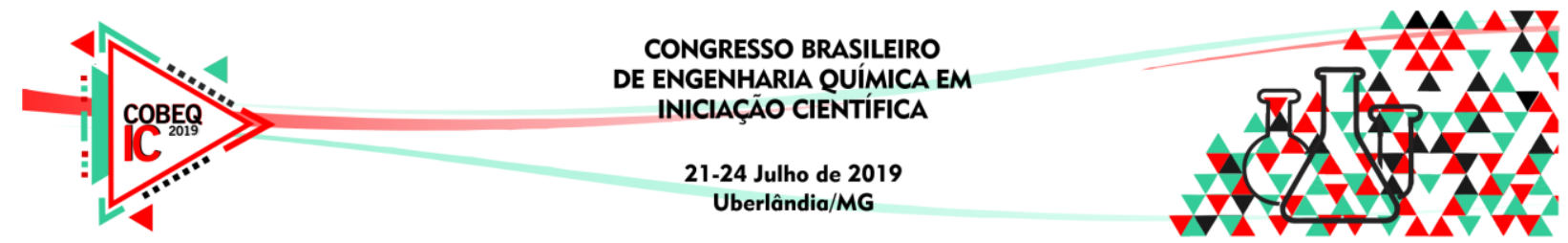

\title{
ESTUDO CINÉTICO DO PROCESSO PRODUTIVO DE CERVEJA ARTESANAL UTILIZANDO MANDIOCA COMO ADJUNTO CERVEJEIRO
}

\author{
D. F. GALVÃO ${ }^{1}$; K. P. RIBEIRO ${ }^{2}$ e G. C. S. POMPÊU ${ }^{2}$ \\ ${ }^{1}$ Centro Universitário de Patos de Minas, Faculdade de Engenharia Química \\ ${ }^{2}$ Universidade Federal de Uberlândia, Pós-Graduação em Biocombustíveis \\ E-mail para contato: karolinepr@unipam.edu.br
}

\begin{abstract}
RESUMO - O estudo objetivou utilizar mandioca como adjunto cervejeiro substituto de parte do malte utilizado na fabricação da cerveja artesanal. Tratou-se de um estudo cinético da fermentação da cerveja do tipo APA (American Pale Ale) puro malte, e com parte do malte substituído por mandioca, visando a comparação dos parâmetros cinéticos de ambas. Foi observado o $\mathrm{pH},{ }^{\circ}$ Brix, Teor alcoólico,teor de células, acidez total, e o rendimento do processo fermentativo. Foi obtido um comportamento fermentativo semelhante, tanto da cerveja puro malte, quanto da que foi utilizada mandioca como substituta para parte do malte utilizado na brassagem. Observou-se um comportamento semelhante das duas formulações quanto aos parâmetros fermentativos e produtos finais, observando uma redução significativa no custo por litro de bebida obtida, para a cerveja com mandioca,se obteve valores de $38,31 \%$ quanto a conversão global da fermentação e $0,35 \mathrm{~g} / \mathrm{L} . \mathrm{h}$, enquanto para a cerveja puro malte, $38,21 \%$ e 0,37 , respectivamente.
\end{abstract}

\section{INTRODUÇÃO}

Na última década, a produção de cerveja no Brasil cresceu impressionantes 64\%, saltando de 8,2 bilhões para 13,4 bilhões de litros anuais, segundo dados do Sistema de Controle de Produção de Bebidas da Receita Federal (SICOBE) (CERVBRASIL, 2014). Atualmente, o setor cervejeiro gera cerca de 2,2 milhões de empregos, com sua receita correspondendo a 1,6\% do Produto Interno Bruto (PIB) (BRASIL, 2017). Em 2016, o Brasil se tornou o terceiro maior produtor mundial de cerveja, fabricando 14,1 bilhões de litros, ficando atrás apenas da China e dos EUA (BRASIL, 2017).

Os adjuntos cervejeiros são utilizados visando diminuir os gastos com matérias primas utilizadas na fabricação da cerveja, uma vez que a matéria prima produzida no Brasil não supre a demanda nacional (D'AVILA et al., 2012). Segundo a Embrapa (2009) apenas 30\% do malte consumido pela indústria cervejeira é produzido no Brasil. Desta forma, a utilização de adjuntos provenientes de matérias primas nacionais diminui os custos do extrato cervejeiro.

O malte da cevada por possuir elevado poder diastásico (capacidade de hidrolisar amido) facilita a utilização de outras matérias-primas amiláceas combinadas com o malte, sendo possível uma maior diversidade de mostos e, consequentemente, de produtos obtidos (EMBRAPA, 2009). 


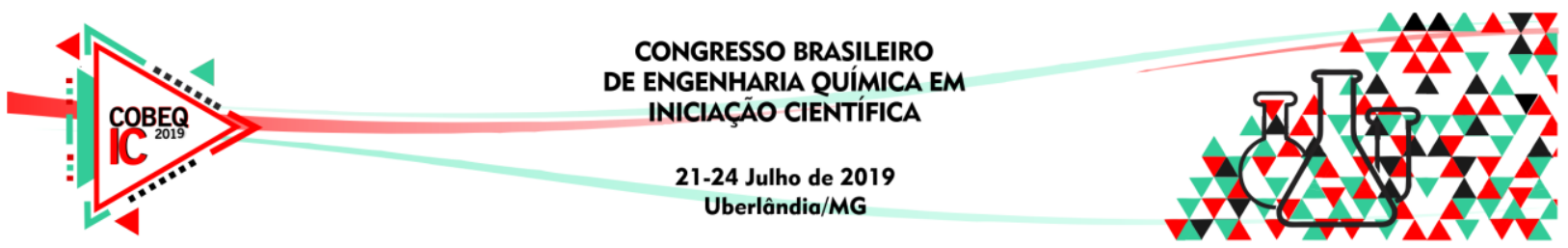

A mandioca (Manihot esculenta Crantz) originária da América do Sul, é um dos principais alimentos energéticos nos países em desenvolvimento. Mais de 100 países a produzem, porém o Brasil é responsável por $10 \%$ da produção mundial, sendo o segundo maior produtor do mundo. É de fácil adaptação situa-se entre os oito primeiros produtos agrícolas do país, em termo de área cultivada e o sexto em valor de produção (EMBRAPA, 2018).

É também amplamente utilizada na obtenção de bebidas e alimentos tradicionais brasileiros, assim como na obtenção de álcool. Além do mais, se comprova a potencialidade do uso de farinhas e féculas de mandioca como adjunto cervejeiro, tal como a obtenção de xarope de alta maltose, por possuir de 2 a $4 \%$ de açúcares fermentescíveis e um alto teor de amido. Desta forma, observa-se a potencialidade da mesma como adjunto cervejeiro e substituto do malte de cevada (VENTURINI FILHO, MENDES, 2004).

O objetivo deste trabalho foi a obtenção e caracterização de uma cerveja artesanal do tipo APA (American Pale Ale) utilizando mandioca como adjunto cervejeiro, substituindo parte do malte utilizado na mesma, bem como o estudo cinético do processo fermentativo e a caracterização físico-química do produto final.

\section{METODOLOGIA}

Foram elaboradas duas cervejas artesanais do tipo APA (American Pale Ale) sendo uma com a substituição de parte do malte por mandioca, e outra contendo apenas malte em sua brassagem. Seguiu-se a metodologia descrita por Aquarone (2001). Para a produção de 50 L, a cervejaria MECBIER com capacidade para 60 litros (fermentador e demais instrumentos que foram utilizados na produção da bebida, como vidrarias e filtros) foram esterilizados com Ácido Peracético com concentração de $15 \%$ V/V.

Para a utilização da mandioca como adjunto cervejeiro, a gelatinização prévia da mesma se fez necessária. Para essa gelatinização, a cada $100 \mathrm{~g}$ de mandioca, foram adicionados 850 $\mathrm{mL}$ de água, aquecendo em banho-maria a $60{ }^{\circ} \mathrm{C}$ por 30 minutos. Para a mosturação de ambas, a água $(50 \mathrm{~L})$ foi aquecida na microcervejaria MECBIER, até a temperatura de $70^{\circ} \mathrm{C}$, adicionando assim todos os maltes previamente moídos e a mandioca gelatinizada na cerveja cuja substituição foi proposta. O processo de cozimento do mosto cervejeiro, foi de 90 minutos em temperatura constante, adicionando $48 \mathrm{~g}$ do lúpulo Amarillo, após 30 minutos de fervura; $28 \mathrm{~g}$ do lúpulo centennial após 45 minutos; e nos últimos 15, adicionou-se $28 \mathrm{~g}$ do lúpulo Columbus.

Após a brassagem, o mosto utilizado na fervura, foi lavado com água a $80^{\circ} \mathrm{C}$, visando a melhor utilização da matéria prima. Após a lavagem do malte, foi adicionada a pastilha de Whirfloc T, para acelerar o processo de decantação. Posteriormente, os mostos passaram por filtração, com auxílio de instrumentos previamente sanitizados, e ao serem filtrados, as bebidas foram transferidas ao fermentadores.

Após a filtração, adicionou-se a levedura aos mostos. As mesmas foram preparadas adicionando $100 \mathrm{~g}$ de levedura a um erlenmeyer previamente sanitizado, com água a $20^{\circ} \mathrm{C}$ e agitação branda, visando não estressar o sistema. Aguardando cerca de 30 minutos antes de transferir o inóculo para o recipiente fermentador juntamente com a bebida. A fermentação ocorreu por 14 dias, com temperatura controlada entre $22^{\circ} \mathrm{C}$ e $24^{\circ} \mathrm{C}$. Após esse período, a cerveja foi filtrada novamente, estando assim, pronta para a adição do Primming (se dará na proporção de $8 \mathrm{~g}$ a cada litro de cerveja) que completará a carbonatação da cerveja. 


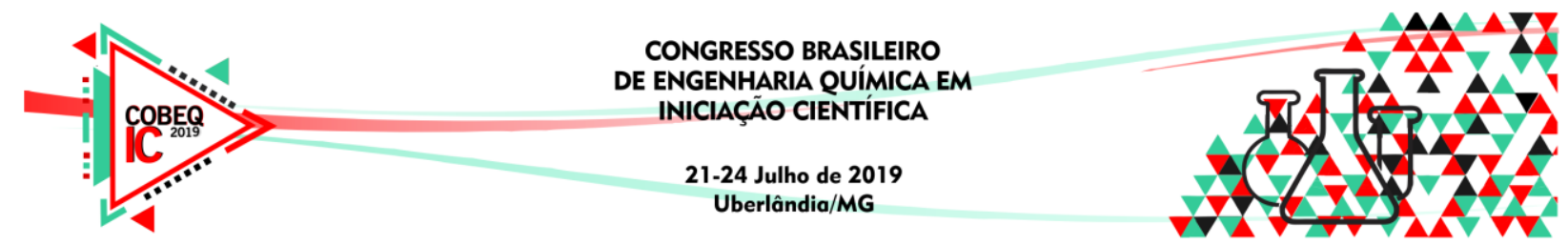

Depois de prontas, as cervejas foram engarrafadas, em garrafas de cor âmbar, com capacidade de $500 \mathrm{~mL}$, previamente sanitizadas com Ácido Peracético, observando um intervalo de cerca de $10 \mathrm{~mL}$ do volume máximo, para que a carbonatação não estourasse a garrafa. Na própria garrafa, a cerveja com a adição do primming, descansou por cerca de 8 dias antes que a mesma fosse aberta para análises posteriores.

\subsection{Análises Físico-Químicas}

As análises do processo fermentativo foram realizadas de acordo com o AOAC (Association of Official Analytical Chemists). Foram realizadas análises de $p \mathrm{H}$, ${ }^{\circ}$ Brix e teor alcóolico. Foram coletadas amostras a cada 24 horas, as quais foram analisados os teores de açúcares, células (Saccharomyces cerevisae) e álcool, para a observação do comportamento cinético celular do processo fermentativo.

\section{RESULTADOS E DISCUSSÃO}

O processo fermentativo foi realizado em dois fermentadores com controle de temperatura fixados entre $20^{\circ} \mathrm{C}$ e $23^{\circ} \mathrm{C}$, sendo um contendo o mosto cervejeiro cujo parte do malte foi substituída por mandioca, e outro sendo puro malte. Os resultados obtidos dos fermentadores estão descritos na Tabela 1:

Tabela 1: Parâmetros do processo fermentativo da Cerveja American Pale Ale com Mandioca (M) e Puro Malte (PM)

\begin{tabular}{|c|c|c|c|c|c|c|c|c|c|c|}
\hline $\begin{array}{c}\text { Tempo } \\
\text { (h) }\end{array}$ & \multicolumn{2}{|c|}{ pH } & \multicolumn{2}{c|}{$\begin{array}{c}\text { Concentração } \\
\text { de sólidos } \\
\text { solúveis }\left({ }^{\circ} \text { Brix) }\right.\end{array}$} & \multicolumn{2}{c|}{$\begin{array}{c}\text { Acidez } \\
\text { Total }(\mathbf{g} / \mathbf{L})\end{array}$} & \multicolumn{2}{c|}{$\begin{array}{c}\text { Concentração de } \\
\text { Células }(\mathbf{g} / \mathbf{L})\end{array}$} & \multicolumn{2}{|c|}{${ }^{\circ} \mathbf{G L}$} \\
\hline & $\mathbf{M}$ & $\mathbf{P M}$ & $\mathbf{M}$ & $\mathbf{P M}$ & $\mathbf{M}$ & $\mathbf{P M}$ & $\mathbf{M}$ & $\mathbf{P M}$ & $\mathbf{M}$ & $\mathbf{P M}$ \\
\hline $\mathbf{0}$ & 4,95 & 5,05 & 16,00 & 17,00 & 2,01 & 8,50 & 6,67 & 6,67 & 0,00 & 0,00 \\
\hline $\mathbf{1 2}$ & 4,97 & 4,91 & 15,80 & 16,90 & 1,47 & 8,45 & 21,33 & 8,67 & 0,14 & 0,00 \\
\hline $\mathbf{3 6}$ & 4,92 & 4,88 & 15,60 & 16,20 & 1,32 & 8,36 & 30,00 & 16,67 & 0,80 & 0,52 \\
\hline $\mathbf{4 8}$ & 4,92 & 4,94 & 15,00 & 16,10 & 1,13 & 8,52 & 34,66 & 23,33 & 2,99 & 0,93 \\
\hline $\mathbf{7 2}$ & 5,00 & 4,76 & 14,70 & 15,10 & 1,08 & 8,72 & 38,00 & 34,00 & 3,27 & 2,34 \\
\hline $\mathbf{9 6}$ & 5,03 & 4,81 & 14,50 & 15,00 & 1,18 & 10,44 & 38,00 & 40,00 & 4,31 & 5,87 \\
\hline $\mathbf{1 0 8}$ & 4,84 & 4,32 & 13,90 & 13,50 & 1,08 & 9,92 & 37,33 & 60,00 & 5,42 & 6,33 \\
\hline $\mathbf{1 3 2}$ & 4,29 & 4,41 & 10,90 & 11,50 & 1,18 & 8,93 & 34,66 & 40,00 & 6,07 & 6,35 \\
\hline $\mathbf{1 4 0}$ & 4,27 & & 9,00 & & 1,08 & & 33,30 & & 6,11 & \\
\hline
\end{tabular}

Segundo Dato (2005), o decaimento da concentração do substrato, se deve ao aumento do número de células e o consumo do mesmo por estas, convertendo assim em etanol e outros compostos. Em ambos os casos podemos observar o decaimento progressivo da concentração do substrato, tal como o aumento da concentração do produto etanol com o passar do tempo que a fermentação ocorre. Já o $p \mathrm{H}$, é considerado de suma importância no processo fermentativo, e interfere diretamente na reprodução celular (LIMA et. al 2001). Além do mais, tanto na cerveja formulada com mandioca como na puro malte foram encontrados valores semelhantes aos descritos como ideais por Aquarone (2001) que diz que a faixa de $\mathbf{p H}$ entre 3,8 e 4,8 permite uma fermentação alcoólica rápida além de inibir bactérias indesejáveis.

\subsection{Estudo Cinético da Fermentação}




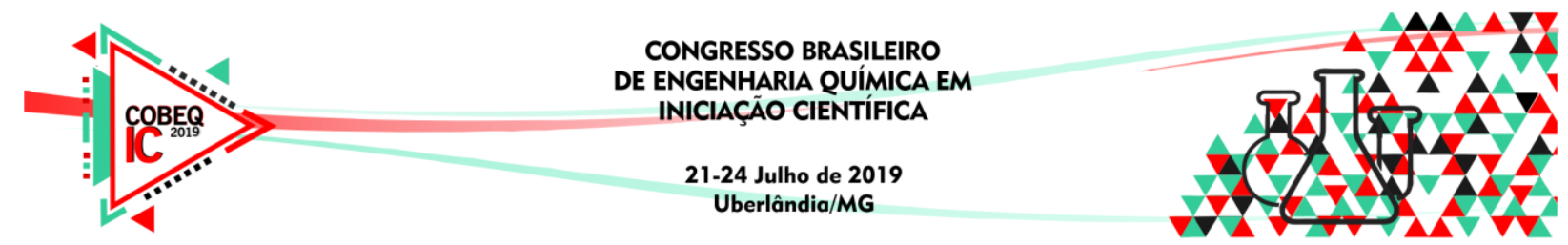

Os resultados quanto aos comportamentos celulares dos processos fermentativos estão dispostos no Gráfico 1. No caso da cerveja com mandioca, pode-se observar que a fase logarítmica (alta taxa de crescimento celular) ocorre aproximadamente nas primeiras 48 horas, seguida de fase de manutenção entre 48 e 108 horas, onde se inicia a fase de morte celular. Já para a cerveja puro malte, observamos uma de alta taxa de crescimento celular até o tempo de 108 horas aproximadamente, não observando a fase de manutenção celular do mesmo, já seguida da fase de morte celular, devido a concentração de etanol no meio fermentativo, tal qual o decaimento da concentração de açúcares no mesmo. Resultados semelhantes foram observados por Andrade (2013).

Gráfico 1: Comportamentos celulares dos processos fermentativos

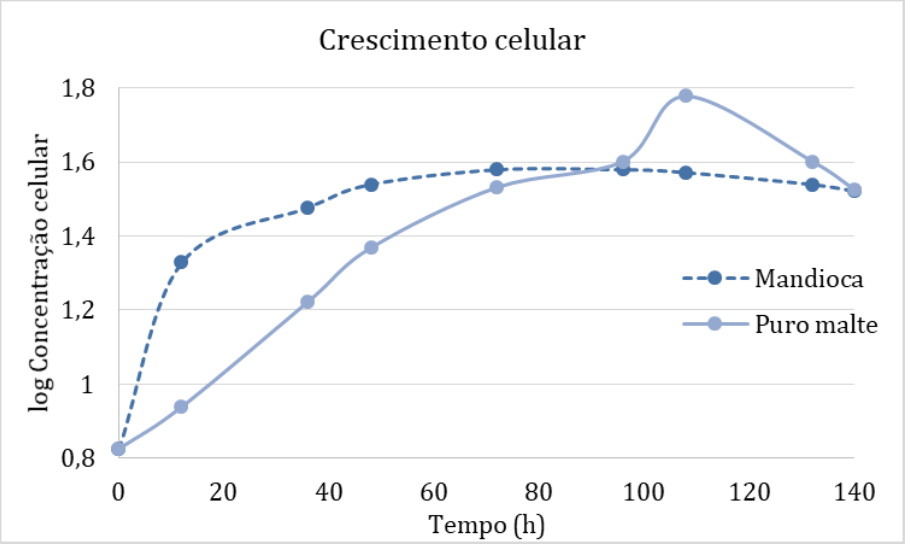

Em ambos os casos, não foi observada fase de latência do meio de cultivo, o que é uma vantagem pois diminui o tempo 'morto' do processo fermentativo. Tal fato foi descrito por Silva (2015), devido ao fato das leveduras comerciais apresentarem uma melhor adaptação ao meio, e com a isso, a inoculação de uma quantidade adequada de leveduras saudáveis é viável e determinante para a redução do período de adaptação e multiplicação das leveduras, proporcionando o início mais rápido da fermentação. Costa (2017) verificou que durante o processo de fermentação realizado pelo mesmo, verificou resultados semelhantes, uma vez que o aumento da contagem de células foi seguido por um declínio de crescimento, caracterizando a morte celular, sem apresentar assim a fase de manutenção das mesmas. Os parâmetros cinéticos das cervejas em questão, estão representados nos Gráficos 2 e 3.

Gráfico 2: Cinética do processo fermentativo da cerveja American Pale Ale com Mandioca

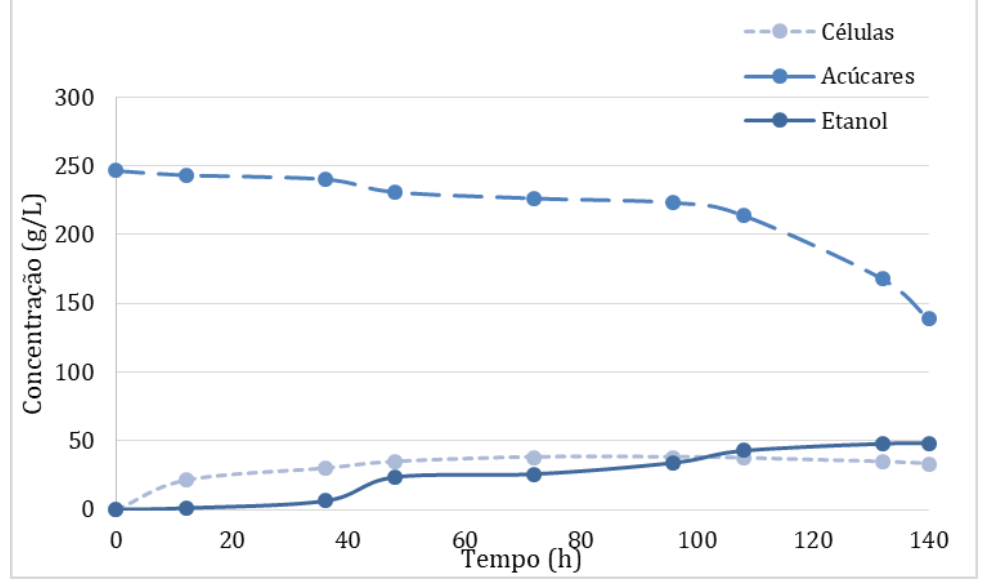




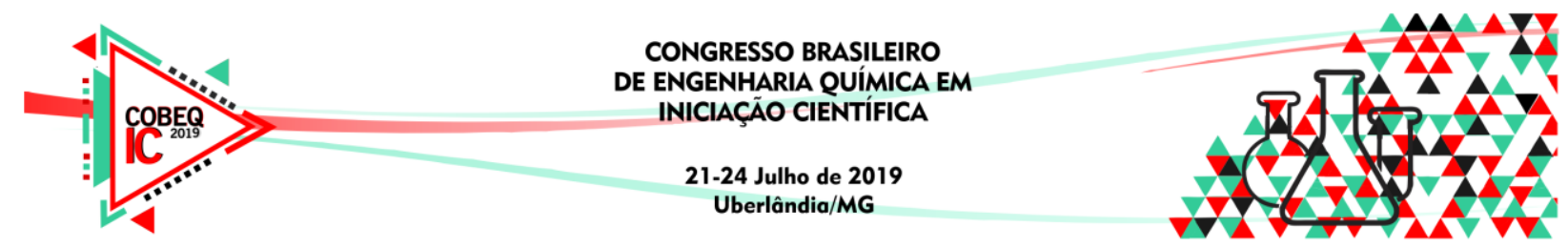

Gráfico 3: Cinética do processo fermentativo da cerveja American Pale Ale Puro Malte

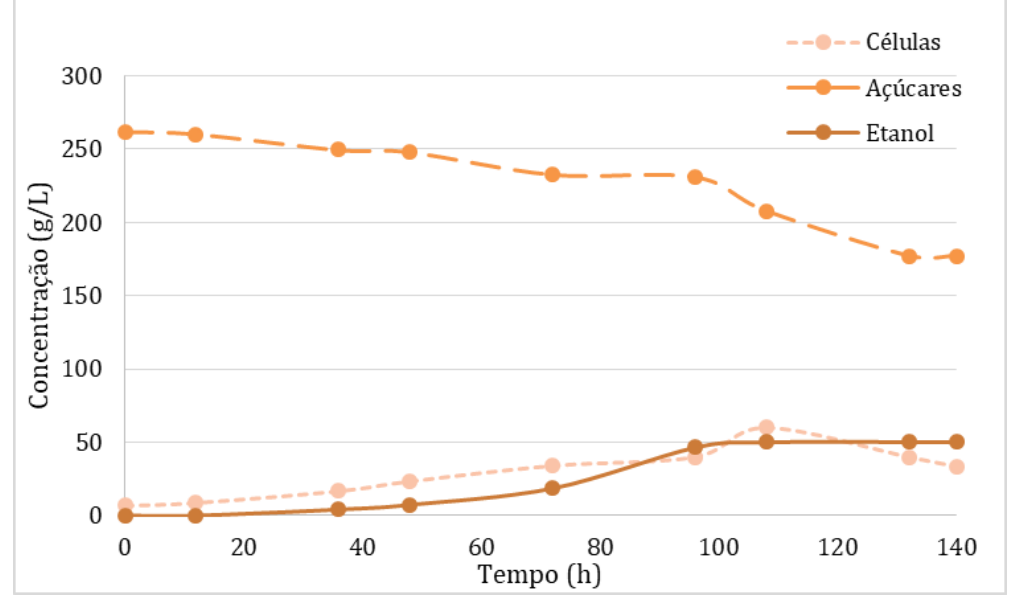

No caso da cerveja com mandioca, pode-se observar que após aproximadamente 40 horas de fermentação, a conversão do substrato em etanol aumenta de forma significativa, e se mantém com baixa variação até aproximadamente 108 horas de processo. Este comportamento pode ser explicado pela alta taxa de crescimento celular, seguido da fase de manutenção da mesma, uma vez que a conversão se mantém com baixa variação até a fase de morte das mesmas, o que é explicado por Andrade (2013), devido a inibição do processo fermentativo devido a presença do produto.

\section{CONCLUSÃO}

A cerveja artesanal do tipo American Pale Ale com adjunto de mandioca, apresentou parâmetros físico-químicos dentro dos padrões exigidos pelo Decreto $\mathrm{N}^{\mathrm{o}} 2.314$, de 4 de setembro de 1997, que rege sobre cervejas e bebidas alcóolicas fermentadas.

A utilização da mandioca como adjunto cervejeiro se mostrou viável, uma vez que os parâmetros cinéticos foram semelhantes aos da cerveja puro malte, os parâmetros físicoquímicos se mostraram dentro da legislação vigente e o baixo custo da mandioca quando comparado ao malte, uma vez que a maioria do malte utilizado na produção nacional de cervejas é importado. Porém, maiores estudos se fazem necessários para a utilização da mesma em larga escala, tendo em vista o processo de hidrólise do amido, além da aceitação desse produto no mercado.

\section{REFERÊNCIAS}

ALMEIDA, Alexandre Nunes; BRAGAGNOLO, Cassiano; CHAGAS, André Luiz Squarize. A demanda de vinho no Brasil: eslasticidades do consumo das famílias e determinantes da importação. 2015, 22 f. TCC (Graduação) - Curso de Economia, Departamento de Economia, Administração, Universidade Federal de São Paulo, Piracicaba, 2015

ANDRADE, Marcelo. O que é clarificação. 2013. Disponível em: $<$ https://vinhopormarceloandrade.wordpress.com/2013/07/06/o-que-e-clarificacaoparte-i/>. Acesso em: 16 maio 2018. 


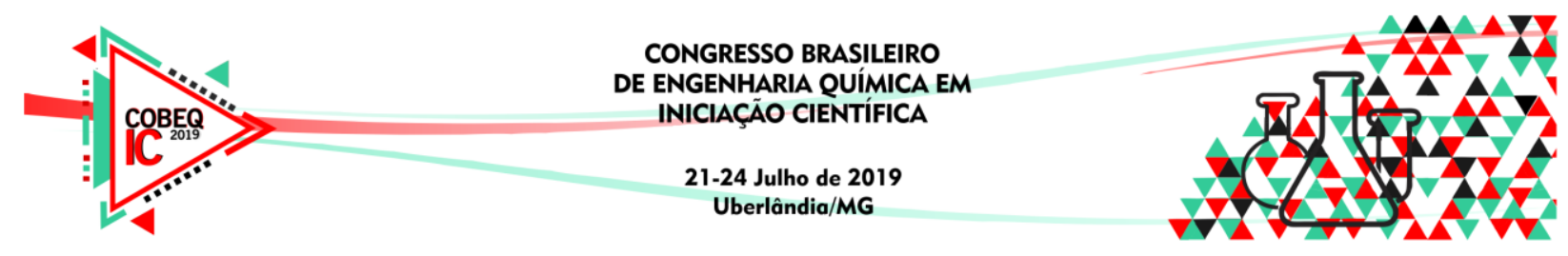

AQUARONE, E.; et al. Biotecnologia Industrial. 4 ed. São Paulo: Edgard Blücher, 2001. p.91-143

BRASIL, Portal. Brasil é o terceiro no ranking mundial de produção de cerveja. 2017. Disponível em: <http://www.brasil.gov.br/economia-e-emprego/2017/08/brasil-e-oterceiro-no-ranking-de-producao-mundial-de-cerveja>. Acesso em: 10 out. 2018.

CASTRO, Orerves Martínez. Obtenção de Cerveja Super concentrada com a utilização de xarope de milho como adjunto de malte. 2014. 144 f. Dissertação (Mestrado) - Curso de Biotecnologia, Departamento de Biotecnologia, Universidade de São Paulo, Lorena, São Paulo, 2014.

CERVBrasil. Anuário2014. Disponível em: <http://cervbrasil.org.br/wpcontent/themes/cerv/pdf/anuariofinal2014.pdf >. Acesso em: 25/03/2018.

COSTA, Rafaela Teixeira Rodrigues do Vale et al. Cinética de produção de bebida mista de mel de abelha e morango. Rev. Verde de Agroec. e Des. Sust., Pombal, v. 12, n. 1, p.9094, 2017.

D'AVILA, Roseane Farias et al. Adjuntos utilizados para produção de cerveja: características e aplicações. Est Tec em Eng, Pelotas, v. 2, n. 8, p.60-68, dez. 2012.

DATO, M. C. F.; PIZAURO JÚNIOR, J. M. E.; MUTTON, M. J. R. Analysis of the secondary compounds produced by Saccharomyces cerevisiae and wild yeast strains during the production of "Cachaça". Bras. Jour of Micro, São Paulo, v. 36, n. 1, p. 7074, jan./mar. 2005.

SILVA, David. Fermentação Cervejeira. 2015. Disponível em: <http://www.condadodacerveja.com.br/aprenda-sobre-o-processo-defermentacao/?utm_source=rss\&utm_medium=rss>. Acesso em: 18 outubro 2018.

Decreto $N^{\circ} 2.314$, de 4 de setembro de 1997 Regulamenta a Lei no 8.918 , de 14 de julho de 1994, que dispõe sobre a padronização, a classificação, o registro, a inspeção, a produção e a fiscalização de bebidas. Diário Oficial da União - Seção 1 - 5/9/1997, Página 19549.

EMBRAPA, 2018. Disponível em <https://www.embrapa.br/mandioca-efruticultura/cultivos/mandioca>. Acesso em: 19/02/2018

EMBRAPA. 2009. Disponível em http://www.embrapa.br/imprensa/noticias/2009/abril/2asemana/reuniao-de-cevadaavalia-safra-naamerica-latina/?searchterm=cevada.

FERREIRA, Suzane Martins et al. PRODUÇÃO DE AÇÚCARES REDUTORES POR HIDRÓLISE ÁCIDA E ENZIMÁTICA DE FARINHA DE ARROZ. Rev Bras de Prod Agroind, Campina Grande, v. 15, n. 4, p.383-390, 2013.

LIMA, Urgel de Almeida et al. Biotecnologia industrial: Processos fermentativos e enzimáticos. São Paulo: Edgard Blucher Ltda, 2001. v 3.

PARENTE, Gisleânia D. L. et al. Cinética da produção do fermentado alcoólico de abacaxi 'pérola' e caracterização da bebida. Verde de Agro e Des Sust, Mossoró - RN, v. 9, p.230-247, jun. 2014. Disponível em:

<http://www.gvaa.com.br/revista/index.php/RVADS/article/view/2752/2252>. Acesso em: 10 mar. 2018.

RIBEIRO, C. A. F.; BLUMER, S. A. G.; HORII, J. Fundamentos de tecnologia sucroalcooleira. Texto para aula; Apostila; Impresso. Piracicaba, v. 2, p. 7-25, 1999

VENTURINI FILHO, W.G.; MENDES, B.P. 2004. Fermentação alcoólica de raízes tropicais. 